\title{
Mediamorfosis y desinformación en la infoesfera: Alfabetización mediática, digital e informacional ante los cambios de hábitos de consumo informativo
}

\section{Mediamorphosis and misinformation in the infosphere: media, digital and information literacy face of changes in information consumption habits}

\author{
Ignacio Aguaded \\ Facultad de Ciencias de la Educación, \\ Departamento Didáctica de la \\ Educación. Universidad de Huelva. \\ ignacio@aguaded.es
}

Fecha de recepción: 14-1-2015

Fecha de revisión: 2-3-2015

\section{Palabras clave:}

Desinformación; mediamorfosis; hábitos de consumo informativo; alfabetización mediática; alfabetización digital; alfabetización informacional.

\section{Resumen}

Desde la reflexión teórica, este trabajo evidencia que el ecosistema comunicacional y digital actual es endógeno y sistémicamente desinformativo, pues se ha convertido paulatinamente en un escenario sobresaturador e infoxicador, atravesado por una dinámica de mediamorfosis, en la que los medios tradicionales buscan competir por la preferencia de la audiencia frente al abanico de propuestas digitales en razón de su subsistencia económica, generalmente intentando difundir contenidos pseudoinformativos de gran valor límbico, pero carente de utilidad en el proceso de toma de decisiones. Así, el presente artículo busca analizar la precitada problemática a través de la revisión de distintas contribuciones académicas multidisciplinares para posteriormente referir aquellas que desde el seno de las teorías de la alfabetización mediática, digital e informacional contribuyen con recomendaciones y estratagemas

\author{
Luis M. Romero-Rodríguez \\ Facultad de Ciencias de la Educación, \\ Departamento Didáctica de la \\ Educación. Universidad de Huelva. \\ Imiguel.rrodriguez@alu.uhu.es
}

Fecha de aceptación: 20-3-2015

Fecha de publicación: 27-3-2015

Keywords:

Misinformation; mediamorphosis; information consumption habits; media literacy; digital literacy; informational literacy.

Abstract

From a theoretical reflection, this work is evidence that the current communicational and digital ecosystem is endogenous and systemically misinformative, as it has gradually become an information overload and infoxicative scenario, traversed by a dynamic of mediamorphosis, in which traditional media are looking to compete for the preference of the audience facing the multiplicity of digital platforms in the way of their economic subsistence, usually spreading pseudo-contents with limbic great value, but lacking useful in the process of decision making. Consequently, this paper analyzes the above problems by reviewing various multidisciplinary academic contributions to later refer those from within the theories of media, digital and information literacy contribute recommendations and pragmatic schemes to cope with the situation. The work focuses on media-digital society in the context of media convergence and multiple 
pragmáticas para hacerle frente a la situación. El trabajo se centra en la sociedad mediático-digital en un contexto de convergencia de medios y múltiples pantallas, esbozando los cambios sociales en el que están insertas actualmente las audiencias. Como resultado se obtuvo que es necesario adaptar una "infodieta" o ecología de medios desde la perspectiva del usuario, alternando momentos de desconexión, sin abandonar los esfuerzos que desde la Educomunicación y la política de comunicación pudieran coadyuvar en la transformación social, con el fin de promover contenidos educativos, culturales e informativos de calidad desde una óptica de pluralismo, participación ciudadana.

\section{Introducción}

La sociedad actual y hasta la propia existencia del hombre que en ella se inserta, es cada vez más dependiente al acceso a Tecnologías de Comunicación e Información. Nuestras interrelaciones, los nodos sociales, las empresas, la economía, la política, la cultura, la educación, entre otros importantes elementos colectivos, son atravesados por la inter-mediación tecnológica, la cual no solo opera como un conjunto de plataformas informáticas, sino como protagonista de insondables cambios en la manera en que nos informamos, nos relacionamos con otras personas e incluso fungimos como partícipes dentro del ágora social que cimientan las redes sociales.

La reducción de los precios de teléfonos inteligentes, tablets y phablets en los últimos años, ha posibilitado un acelerado y constante incremento de usuarios de Internet $\mathrm{y}$, por ende, una paulatina contracción de brechas digitales asociadas al poder adquisitivo. En el caso español, para 2014 el 76,2\% de la población tenía acceso a la red y $74,4 \%$ de los hogares disponía de conexión, casi 5 puntos más que en 2013 y más de 7 puntos con respecto al 2012. Del total de usuarios reflejados, $67,1 \%$ participaba activamente en redes sociales de carácter general -Facebook, Twitter, Tuenti- (INE, 2014). screens, outlining the social changes that are currently embedded audiences. Obtained results showed the need to adapt an "infodiet" or media ecology from the user's perspective, alternating moments of disconnection, without deserting the efforts that Educommunication and communication policy could contribute in social transformation, in order promote educational, cultural and informative content from the perspective of pluralism, citizen participation and pragmatic reconstruction towards public service media.

Los datos globales también dan meridiana evidencia del exponencial incremento de la demanda de conexión a Internet. Para finales de 2013, se estimaba que el $96 \%$ de la población mundial poseía un dispositivo de telefonía móvil, lo que significa aproximadamente unos 6.800 millones de suscriptores, habiendo sido el continente africano el que tuvo el crecimiento más elevado con 11 puntos respecto al año anterior; mientras se calculaba que $40 \%$ de la población mundial estaba conectada a Internet (ITU, 2013), cifra que demuestra el exponencial incremento de usuarios, duplicándose en número con respecto a la data de 2009 .

Fuera de los datos estadísticos, que sin duda nos dan una visión numérica de la realidad, el acceso a Internet también ha mutado las capacidades de organización social de los ciudadanos. Vale la pena recordar movimientos sociales como \#OcuppyWallStreet en Estados Unidos, con sus réplicas en México, España, Reino Unido, Portugal, Grecia, Australia, Alemania, Japón, Países Bajos, Argelia e Israel, comenzaban con un simple mensaje en las redes sociales que servían como germen del caldo de cultivo de la indignación popular. Así también sucedía en España con el Movimiento \#15-M, donde las redes de interconexión social fungieron como 
convocantes a las actividades de organización y manifestación, sin olvidar por supuesto el inmenso protagonismo que tuvieron las TIC en la denominada Primavera Árabe que se inició en Túnez pero que tuvo réplicas casi inmediatas en todo el norte del continente africano, en especial en Egipto, Libia, Siria, Sahara Occidental, Líbano, Jordania, Mauritania, Sudán, Omán, Arabia Saudita, Yemen y Marruecos, países estos donde hace apenas pocos años era impensable la amplia penetración de Internet y mucho menos movimientos ciudadanos contrarios a sus regímenes (Soengas, 2013).

Internet, más que un simple cambio de pantallas o plataformas, ha significado sin dudas una morfosis social, modificando enteramente los esquemas tradicionales del

\section{Objetivos e hipótesis}

El presente análisis se realiza a partir de la interrelación teórico-pragmática del fenómeno de la desinformación en el contexto de los cambios que han venido gestándose a partir de la masificación de Internet y las redes sociales, más que como una anomalía aplicada por factores externos, un elemento endógeno que se inserta permanentemente en el ecosistema comunicacional, con el fin de proponer un modelo de integración de las competencias digitales, mediáticas e informacionales que coadyuve en la atenuación de la problemática. En este sentido, el presente artículo pretende como objetivo general analizar los factores cardinales que inoculan la desinformación endógena en la infoesfera, a través del examen de: 1) La sobresaturación informativa y la amplitud relacional; 2) La ausencia de filtrados editoriales y el cambio del modelo periodístico y; 3) El auge de los contenidos pseudo-informativos; para a posteriori revisar aquellos aportes pragmáticos que

\section{Material y métodos}

El presente marco teórico-contextual parte de seleccionar unidades de análisis flujo comunicativo, otrora centralizados enteramente por los gobiernos, los medios de comunicación tradicionales y aquellos con acceso preferencial al podio discursivo social. En este nuevo escenario, resulta complejo y hasta coercitivo mantener el control de la in-formación y las comunicaciones (Etling, Kelly, Faris \& Palfrey, 2009), sirviendo el ecosistema digital como suplemento de los medios tradicionales e incluso opacándolos en la triangulación poder-medios-sociedad; que además de ser aprovechados por su gran capacidad informativa y de convocatoria, también se constituyen como garantes de elementos probatorios de conculcaciones de derechos fundamentales y evidencias de represión sistemática de manifestaciones sin barrera geográfica alguna.

desde la teoría de las competencias digitales, comunicativas e informacionales se han propuesto para hacer frente a la situación.

Como hipótesis de partida (H1), hemos de considerar que la sobresaturación informativa es uno de los elementos configurativos de la infoesfera actual, hecho el cual lejos de ser tendiente a una normalización cuantitativa, mantiene un crecimiento exponencial. En segundo lugar (H2), se reflexionará sobre cómo la crisis de los medios de comunicación tradicionales ha cambiado las interrelaciones pregnancia-saliencia ideológica, construyendo medios de comunicación cada vez más asépticos y estandarizados para intentar alcanzar una mayor porción de audiencia. Por último (H3), se intentará revisar el fenómeno del apogeo de los contenidos pseudo-informativos en la red, como tercer elemento endógeno característico de los nuevos espacios digitales.

bibliográficas, hemerográficas, científicas y estadísticas, con especial atención a aquellos 
resultados de esfuerzos académicos en publicaciones de alto índice de impacto en ejes temáticos de las ciencias sociales, también considerando tópicos de otras disciplinas y áreas del conocimiento que han contribuido en el análisis del efecto desinformativo en Internet. Asimismo se revisarán algunas de las contribuciones más importantes que desde el seno de las investigaciones acerca de las competencias digitales, mediáticas e informacionales se han resuelto para evitar o al menos atenuar el efecto desinformativo. Para esta investigación documental serán tomadas como categorías de análisis aquellos trabajos que contengan los descriptores: "desinformación digital", "sobresaturación informativa", "infopolución", "infoxicación", "infodieta", "pseudo-información", "mediamorfosis", "crisis de los medios de comunicación", "competencia digital", "competencia comunicativas" y "competencias comunicacionales", con sus equivalentes idiomáticos en inglés, francés, italiano y portugués; para luego de realizada la ficha bibliográfica y su análisis correspondiente, filtrar aquellos autores que advierten sobre la necesidad de analizar los cambios del sistema a la luz de la problemática desinformativa y proponen estratagemas y tácticas pragmáticas frente a la referida situación.

\section{La desinformación endógeno-sistémica}

Como todo cambio del sistema, la masificación de Internet también ha traído consigo nuevas problemáticas que van desde la sobresaturación e infoxicación del espectro comunicativo (Shenk, 2003: 396-397; Cornella, 2010; Carr, 2011; Romero-Rodríguez, 2014: 33-35), el auge del consumo de contenidos pseudo-informativos (Sartori, 1998; Ortega, 2006), hasta una profundización de la crisis de los medios tradicionales que ha fomentado un decrecimiento de espacios laborales para periodistas, un cambio de interrelación ideológica pregnancia-saliencia (Thom, 1992: 14; López-García, 2004: 23) y la multiplicidad de informaciones sin filtrado de verificación editorial, cuestiones estas que pueden constituirse como un escenario idóneo para la desinformación estructural en el ecosistema, tomando dimensiones insospechadas y para las que ninguna institución social estaba preparada (Pérez-Rodríguez, 2003; PérezTornero, 2005).

El riesgo de la desinformación en Internet, en especial en las redes sociales, subyace en la propia interactividad y permeabilidad del trinomio receptor-productor-difusor de contenidos -prosumo- con el que está compuesta la información en línea, siendo casi imposible para aquellos carentes de suficientes niveles de competencia digital, informacional y comunicativa, distinguir entre información, rumores y desinformación. Los cibernautas suelen disfrutar compartiendo información, sobre todo si es novedosa, aún incluso cuando quien difunde no crea en la veracidad de lo que publica (Karlova \& Fisher, 2012: 2). Esta situación puede deberse a que la propia existencia en el mundo digital depende precisamente de la capacidad de bien o generar o de difundir continuamente contenidos para su círculo social, como también de que quien ejerce el rol de prosumidor en términos de verificación, fuentes o pertinencia lógica de la información, no tiene las competencias suficientes para fungir como mediador informativo. El inconveniente que se suscita con este modelo de producción es que el factor multiplicador que tienen las redes sociales usualmente hace que el mensaje desinformativo no solo llegue al entorno comunicacional directo del emisor, sino que sea redifundido y hasta viralizado por otros prosumidores fuera de su ámbito de influencia digital directa. 


\subsection{La sobresaturación y la asimilación cognitiva}

La sobresaturación del espectro informativo es el primer problema sistémico que se suscita con la masificación de Internet. Hace solo 10 años se estimaba que una sola edición del diario The New York Times contenía más información que la que manejaba un lon-dinense común del siglo XVII (Shenk, 2003: 396). La actual hiperproducción e hiper-distribución informativa traspasa cualquier barrera geográfica, en la que se unen los contenidos generados por los medios tradicionales -prensa, radio, televisión- con aquellas distribuidas por Internet y las redes sociales, superando con creces la capacidad de procesamiento y asimilación cognitiva (Stewart, Moninger, Heideman \& ReaganCirincione, 1992) y obligando al individuo a adaptarse frente a las sobrecargas de estímulos, bien dedicándole menor tiempo a cada uno, realizando un mecanismo de bloqueo o escotomización inconsciente o instalando filtros cognitivos para mantener la cantidad de ingreso informacional a niveles manejables (Milgram, 2010).

Se estima que para finales de 2013, por cada minuto fueron enviados 204 millones de correos electrónicos, el motor de búsqueda Google recibió 2 millones de accesos y en las redes sociales se dieron cerca de $850 \mathrm{mil}$ interacciones (Nielsen, 2014), lo que acumulaba en el Big Data de Internet para ese año 2,7 zettabytes (International Data Corporation, 2013). Nuestra propia barrera física, cognitiva y memorística hace imposible que una persona pueda acceder y mucho menos atender a la ciclópea cantidad de informaciones que se generan durante su vida, en el entendido que nuestra evolución cerebral ha permanecido inerte por más de 50.000 años (Shenk, 2003: 398).

Según estadísticas recientes, los adolescentes alemanes y estadounidenses pasan más de siete horas y media diarias usando la convergencia de medios tradicionales, multimedia y digitales (Aguaded, 2014). En el caso español se estima que mensualmente se mantiene un consumo de telefonía móvil una media de 88 minutos, se envían 15 SMS $\mathrm{y}$ se utilizan en promedio 388 megabytes de datos móviles (Romero-Rodríguez, 2014), llegando a usar los dispositivos móviles para acceso a datos una media de 13.3 horas semanales -1 hora con 50 minutos diarios-, incorporando a esto el hábito de consumo de medios tradicionales como la televisión, que tiene un promedio de 13 horas a la semana -1 hora con 45 minutos diarios-, seguido de la prensa con 4 horas y media y las revistas con 3 horas y media semanales, totalizando el hábito de consumo mediático (tradicional y digital) en más de 4 horas y media al día (IAB Europe, 2014).

Con respecto a las consecuencia psicológicas, la sobresaturación genera confusión en el proceso de toma de decisiones y el decrecimiento de la efectividad del filtrado de la información (Malhotra, 1984: 438), disminución de la tolerancia de la frustración y complejidad cognitiva (Rotten, Olszewski, Charleton \& Soler, 1978: 360-365) y deterioro en el juicio (Jacoby, 1977).

Sin lugar a dudas, la tendencia a la opulencia informativa es aumentativa por cada segundo que se mantenga la producción y difusión de contenidos, que coincide con la socialización de la tecnología, la interactividad y la reestructuración del sistema mediático que ha pasado de ser centralizado o semicentralizado a una diversificación, desconcentración y descentralización de los nodos de producción, difusión y redifusión informativa (Cornella, 2010). La desinformación queda insertada como elemento fundacional del ecosistema, en la medida en que es imposible informarse, sin a la vez quedar desinformados (LópezGarcía, 2004; Romero-Rodríguez, 2014).

\subsection{La mediamorfosis y el cambio del modelo de periodismo}

Los medios de comunicación históricamente se han implantado en la sociedad con una 
paradoja: ellos construyen discursiva, narrativa y transdiegéticamente las realidades socializadas (Searle, 1997; Floridi, 2014), pero a la vez dependen de condiciones precomunicativas y perceptivas del sistema en el que se insertan, creado mayormente por su producción informativa. Así, el periodismo no es una variable independiente respecto del sistema económico, político y social, sino que influye y a la vez es intervenido por el mismo (Lippman, 1922).

La masificación y uso consuetudinario de plataformas digitales que ha traído Internet y las redes sociales, paulatinamente pero de forma constante han cambiado los hábitos de consumo informativo, sea por sus características de inmediatez, omnipresencia, interacción y en muchos casos hasta gratuidad, desplazando a un segundo plano la necesidad de acceso a los medios tradicionales para cubrir nuestra necesidad de estar informados. En segundo lugar, la recesión económica mundial que iniciaba en 2008 y que aun, siete años más tarde, mantiene sus efectos en varios países, asesta otro duro y certero impacto al tejido industrial de la comunicación compuesto por los medios de comunicación, las agencias de noticias, el sector publicitario y por supuesto los anunciantes.

En el caso español, entre 2008 y 2013, han sido cerrados 284 medios de comunicación -184 revistas, 31 diarios, 29 televisoras regionales y autonómicas-, ya que la inversión publicitaria ha mermado más de $50 \%$ con pérdidas económicas de $31 \%$ en el sector y destruyendo 11.151 puestos de trabajo (Asociación de la Prensa de Madrid, 2013).

Para adaptarse a los cambios en razón de su supervivencia, los medios han optado por el abaratamiento de costos de producción, bien sea prescindiendo de sus corresponsalías en el extranjero, disminuyendo su tirada y producción propia, acudiendo a agencias in-ternacionales de noticias, cambiando su tradicional plataforma a soportes digitales, mermar las condiciones laborales del personal periodístico e incluso reduciendo el personal al mínimo operativo posible, cuestiones que afectan en inmensa medida la calidad informativa y el resultado de los productos de los medios (De-Pablos \& Mateos-Martín, 2004; Romero-Rodríguez, 2014).
La situación de por sí se agrava con la concentración de mass-media característica de finales del siglo XX, en la cual conglomerados de corporaciones nacionales e internacionales compilan un tejido empresarial complejo que reúnen prensa, editoriales, emisoras de radio, cadenas de televisión y más recientemente medios multimedia, digitales y proveedores de Internet, todo en un inmenso laberinto de Creta de figuras mercantiles. De esta manera, las grandes corporaciones mediáticas, en continua competencia por cuotas del mercado e influencia, generan dumping informacional, por lo que se hace casi imposible el resurgimiento de nuevos medios en los espacios tradicionales.

- A la vez aparece el denominado "efecto ventrílocuo" (Arraez, 1998), en el cual concurre la apariencia de existir diversidad de medios, visiones y reinterpretaciones de las realidades sociales, aunque no exista tal pluralidad en los actores intermediarios. Esta situación ocurre principalmente por 5 causas (Romero-Rodríguez, 2014):

- Los conglomerados empresariales reutilizan las mismas informaciones e interpretaciones de los acontecimientos en los medios adscritos a su entramado organizacional, por lo que las informaciones tienen un solo enfoque a veces parafraseado.

- La sobreutilización de las agencias internacionales de noticias, en especial las denominadas Big Five (Reuters, Associate Press, Agence-France-Presse, EFE), forjan una cobertura estandarizada de las informaciones internacionales según la perspectiva de estas agencias.

- La reducción de nóminas de periodistas y el incremento cuantitativo del trabajo hacen necesario que muchos opten por dividirse las pautas con pares de otros medios para luego compartir las informaciones.

- Aparece el "periodismo autómata" como consecuencia de la propia crisis laboral en los medios. En este sentido, se le otorga más espacio a los contenidos de entretenimiento, opinión y notas de prensa provenientes de gabinetes de comunicación, mientras son cada vez menos presenciales los géneros interpretativos y de investigación, que exigen 
mayor esfuerzo y concentración laboral.

- Muchos medios digitales funcionan como hubs de informaciones provenientes de los medios tradicionales, así como los contenidos informativos más presentes en las redes sociales, por lo que lejos de significar una mayor pluralidad informativa, el ecosistema funge como una continua perífrasis y pará-frasis lexical, un pluralismo virtual de información estandarizada.

Todo lo anterior ha venido constituyéndose como caldo de cultivo de un nuevo modelo de periodismo que busca competir con la inmediatez, gratuidad y masividad de las informaciones de las redes sociales, apostando contra la profundidad y desarrollo de los acontecimientos, convirtiendo así la cobertura informativa en "productos enlatados", estandarizados y superficiales, dependiente de los cambios de dinámica de la agenda pública, por lo que los medios han llegado a desarrollar, y sus usuarios a aceptar tácitamente, un sistema informativo el cual asimila la contradicción sin inmutarse (Marcuse, 1968; López-García, 2004: 22).

Por otra parte, el proceso de mediamorfosis ha traído consigo un cambio en las relaciones pregnancia-saliencia ideológica (Thom, 1992: 14; López-García, 2004: 23). Antes de la progresiva popularidad de Internet, en cada país competían diversos medios que representaban posiciones ideológicas, por lo que cada ciudadano consumía aquella información del medio más próximo a su forma de pensamiento. En este caso, la pregnancia $(P)$ se constituye como las corrientes de opinión y el sesgo editorial del medio que se proyectan hacia las audiencias -saliencia $(S)$ - que era pasiva en su recepción, pero

\subsection{El auge de los pseudo-contenidos}

La avidez por el consumo de contenidos vacíos, inútiles para la toma de decisiones e infoxicadores, complementa el trinomio de la desinformación sistémico-estructural del ecosistema actual, esta vez fungiendo la propia audiencia como víctima propiciatoria del fenómeno desinformativo (RomeroRodríguez, 2014: 48). Un contenido que decodificaba, procesaba cognitivamente, recodificaba y se volvía a construir el discurso mediático en el seno social de la saliencia ahora como emisores- generando una nueva pregnancia $\left(P^{\prime}\right)$.

$$
\boldsymbol{P} \cap \boldsymbol{S} \approx \boldsymbol{P}
$$

En el escenario actual, los medios de comunicación intentan esconder su ideología en el marco de mostrarse como independientes, autónomos, objetivos e imparciales, con el fin de asegurar una mayor porción de audiencia general no estratificada ideológicamente. Para ello, además de estandarizar las informaciones, tal como se refiere ut supra, se dividen los espacios y secciones casi de idéntica forma, además de incluir columnistas, articulistas, tertulianos y panelistas de distintas corrientes de pensamiento. Sobre este particular, pareciere que los medios tienen el rol actual de ser unidades de saliencia $(S)$-tendientes a la asepsia informacionalque intentan tímidamente emitir pregnancias $(P)$, con el fin de generar en las audiencias nuevas formas de pregnancias $\left(P^{\prime}\right)$.

\section{$\boldsymbol{S} \cap \boldsymbol{P} \approx \boldsymbol{P}^{\prime}$}

Aunque la situación anterior no es del todo negativa, pues los medios de comunicación teleológicamente deben ser lo más imparciales y objetivos en la medida de sus posibilidades, esta "asepsia informativa" requiere que el lector tenga las suficientes competencias en las materias de la res pública (economía, política, derecho, sociedad, entre otras), para configurar y reinterpretar con suficiencia la magnitud de la realidad de los acontecimientos que se intentan informar. Es decir, el mantener las informaciones libres de análisis y crítica -así sea desde el razonamiento ideológico- influye en la comprensión a veces técnica de los contenidos informativos.

pseudo-informativo es definido como un acontecimiento que discursivamente se construye o es prefabricado (Sartori, 2012: 27) para que tenga cabida en los factores de interés de la audiencia, pero que carece absolutamente de relevancia, lo que en palabras de Ortega (2006) es el "periodismo de la no-información". 
La pseudo-información tiene mayor presencia en los contenidos de medios digitales y redes sociales, aunque no excluye que los medios tradicionales estén cada vez más optando por la creación de pseudo-contenidos de carácter límbico, desviándose hacia la otrora popular "tabloidización" en función de su competencia por la preferencia del consumidor.

Un claro ejemplo de lo anterior es BuzzFeed (www.buzzfeed.com), medio digital que se autodefine como "el medio de comunicación de la era social" y cuyos contenidos son en $\mathrm{su}$ inmensa mayoría pseudo-informaciones como listados, información de farándula, gifs animados, vines, memes y vídeos de entretenimiento. Fundada en 2006, BuzzFeed es una página que actualiza contenidos con alta tasa de viralidad en inglés, español, francés y portugués, que consigue el $75 \%$ de sus visitas a través de los timeline o historiales de las principales redes sociales como Facebook, Twitter y YouTube.

Poniendo en evidencia el impacto que este portal ha tenido en el consumo de contenidos, para finales de 2014 solo su página principal (versión estadounidense) reportó casi 200 millones de visitantes únicos y 750 millones de visitas por mes, un crecimiento de $153 \%$ frente a sus cifras de 2013 y $350 \%$ con respecto al 2012, con una tasa actual de progresión mensual mayor de $30 \%$, colocándose actualmente en la posición 93 del ranking mundial de visitas digitales -en 2012 tenía el puesto 123-, muy por encima de la web de The Guardian (157), Forbes (158), Der Spiegel (186), BBC (204), The Tele-graph (235), USA Today (258), Reuters (267), NBC News (282) o Time (346) (Alexa, 2014) y cotizándose la marca en un estimado de 636,9 millones de euros, incluso más que el tradicional Washington Post.

Para detectar la existencia y nivel de desarrollo de este "periodismo banalizado", existen 3 elementos fundamentales a tomar en consideración: 1) La selección de los pseudo-acontecimientos se centran en el interés humano y el sensacionalismo frente a la poca atención de las mayorías a las informaciones elitistas (Humanes, 2006: 53$54)$; 2) Internet ha ampliado el protagonismo de los espacios dedicados al ocio y el entretenimiento, sacrificando los objetivos de los medios tradicionales de informar y educar y; 3) La hiperconexión compulsiva, añade una obsesión por la comunicación vacía de contenidos como pasatiempo regular (Aguaded, 2014: 7).

Por su parte los medios audiovisuales buscando no quedarse atrás en la banalización de los contenidos, han impulsado la producción de programación de telerrealidad (realities) para poder adaptarse a la situación de competencia en la lógica del mercado que significa la coexistencia en la parrilla de multiplicidad de canales, aunado con la necesidad de subsistencia frente a la infinidad de formatos que comienzan a ver luz en la televisión digital y en los canales de YouTube y otros portales de videos gratuitos en Internet. Este tipo de programación, lejos de informar o educar, presenta un imaginario colectivo, económico en su producción, con gran presencia de contravalores -trivialidad, inanidad, desmerecimiento del esfuerzo, egoísmo, violencia, encono, machismo-, fomentando la falta de interés por los asuntos públicos (Cáceres-Zapatero, 2013:670).

Los audímetros de la televisión española registraron el 21 de julio de 2000 que 7 de cada 10 telespectadores se encontraban frente a su televisor viendo la gala final de la primera edición de "Gran Hermano" Telecinco-, congregando la serie en promedio 9.105.000 personas de audiencia cautiva, lo que representa un 70,8\% de cuota de pantalla (Palomo, 2014), marcando así lo que sería el primer hito de la telerrealidad española y que sería el inicio de un cambio de formatos por la preferencia del consumidor, incluso en las televisoras públicas, tanto nacionales como de las comunidades autónomas, regionales y locales.

La predilección de los consumidores por este tipo de programación, la lógica del mercado de producción de "enlatados" de bajo costo y fuente inagotable de temporadas, así como la posibilidad de mezcla de formatos (mixtificación) en las que se pueden combinar elementos de telerrealidad con concursos, el coaching, el talent show, entre otros, han sido las razones principales por las que las televisoras han optado por la banalización de los contenidos, incrementando la oferta de programación de entretenimiento mientras 
se sacrifican los contenidos educativos e informativos. En este sentido, es necesario comprender que los medios de comunicación son ante todo empresas cuyo producto debe adaptarse a la dinámica y preferencia de sus consumidores, por lo que la audiencia funge a la vez como propiciatoria y víctima de la situación desinformativa por su propia preferencia de consumo de programación.

\section{Necesidad de integración de la alfabetización mediática e informacional}

Las diferentes perspectivas y discusiones que se han suscitado sobre la relación entre los dos campos, el primero (alfabetización mediática) más encaminado en revisar a los medios de comunicación como una lente a través de la cual ver el mundo y expresarse uno mismo (Livingstone, Couvering \& Thumim, 2005: 16), siendo de mayor interés académico en disciplinas de las ciencias sociales como la educación, la comunicación, la psicología o la salud ocupacional (Lee \& So, 2014: 137); el segundo (alfabetización informacional) considera a la alfabetización mediática como una subcategoría de su área de estudio (Gutiérrez \& Tyner, 2012:34), pues el objeto de este campo consiste en analizar la información y los contenidos sin importar su emisor (Boekhorst, 2012; Kurbanoglu, 2012), concentrándose su interés en disciplinas como las ciencias de la información, la biblioteconomía, la informática, aunque también en la educación (Lee \& So, 2014: 137).

La UNESCO (2012) hacía un llamado urgente a integrar ambos campos de estudio en un solo conjunto combinado de competencias necesarias para el desarrollo integral de la vida y el ámbito profesional, a pesar de los propios límites materiales y de reconocimiento mutuo (Badke, 2009). Aunque la alfabetización informacional resulta más extensa que su par mediática, pero más reducida en sus disciplinas de aplicación, ambos campos coinciden en ciertos aspectos y comparten preocupaciones comunes, objetivos y directrices futuras (Lee \& So, 2014: 145), entre las que se encuentran los contenidos, la información y los medios digitales. En consecuencia, la cooperación entre ambas ramas de estudio pueden contribuir y aunar esfuerzos para establecer lineamientos de hábitos de consumo digital, a la par que se suscitan los intempestivos cambios de plataformas y maneras de comunicarse, integrados a los problemas conexos explicados en referencia. Independientemente de los debates, encuentros y desencuentros entre ambas áreas de estudio, ante los medios no cabe más opción que aprender a convivir con ellos (Agua-ded, 2014), intentando que desde el propio seno de la educación para la infociudadanía nazcan estrategias puntuales para el aprendizaje de un correcto consumo de los contenidos.

\subsection{La "infodieta" y la "comunicación slow"}

Frente a la problemática de la sobresaturación informativa y los límites de la asimilación cognitiva, debe buscarse el equilibrio cantidad-calidad de los contenidos a los que se accede, en los que la habilidad teóricopragmática estrechan su cauce, teniendo en consideración en primera mano que es imposible filtrar o limitar los contenidos sin que esa colación tenga de por sí elementos desinformativos, ya que toda clasificación informativa viene impuesta con una carga de valores, experiencias y marcos de referencia subjetivos (Romero-Rodríguez, 2014).

Como respuesta a la cibercultura caracterizada por la vertiginosa velocidad de las interrelaciones y la manera en cómo nos informamos se aboga por el "movimiento slow" el cual apuesta por un estilo de vida más pausado -tanto en aspectos gastronómicos, laborales, de ocio, como contrario a la hiperconexión- (Honoré, 2004; SerranoPuche, 2013: 208). Al igual que en la industria 
de la alimentación existen calorías baratas comidas rápidas, refrescos, tentempiés-, cuyo coste es económico y su sabor es aderezado con azúcares, sal o grasas sobresaturadas, en exceso perjudiciales para nuestro cuerpo, exactamente lo mismo sucede con el exceso de información en forma de contenidos banalizados y vacíos que no transmiten informaciones de utilidad sino refuerzos sentimentales en forma de interacción social (Johnson, 2012: 29).

El movimiento de "comunicación slow" (Hanson, 2007; Freeman, 2009; Wajcman, Bittman \& Brown, 2009; Pérez-Latre, 2011; Victoria-Mas, Gómez-Tinoco \& ArjonaMartín, 2012; Serrano-Puche, 2013, 2014) hace un llamado a establecer períodos regulares de desconexión digital para fomentar la comunicación interpersonal directa, abogando por las actividades de ocio fuera de las tecnologías digitales, recuperándose la capacidad de atención, crítica y análisis (Jantz, 2012). De esta manera, según los teóricos en referencia, se conseguiría que los momentos de conexión sean más enriquecedores, pues al estar continuamente conectado y por el flujo incesante de información, se reduce la productividad y eficacia del consumo. Caso contrario.

Se recomienda que la dieta digital esté estructurada en cuatro pasos (Sieberg, 2011; Se-rrano-Puche, 2014): 1) Repensar el tiempo diario que se le dedica a la navegación digital más allá de lo necesario por razones laborales y de qué modo ese tiempo se ha perdido en detrimento de las relaciones familiares y sociales, de horas de sueño y de actividad física; b) Una fase de "desinfoxicación" digital y abstinencia en el uso de tecnologías de manera progresiva; c) Reconectarse nuevamente partiendo de un cronograma de hábito saludable con momentos de desconexión diaria y; d) Adquirir una actitud "slow" de manera que la relación con las tecnologías y la relación interpersonal directa tengan un equilibrio.

\subsection{La necesaria reformulación de los medios desde las audiencias}

Hacer frente a la dinámica de hiperproducción de pseudo-contenidos, así como a la estandarización y asepsia informativa producto de la mediamorfosis, no deja de ser dificultoso, pues la naturaleza económica de los medios y del mercado, así como las preferencias de consumo de las audiencias son los que crean la situación idónea para lo que ocurre en el ecosistema actual.

- El cambio de esta situación debe venir inicialmente de varias estratagemas, cuyas iniciativas parten de la educación en medios, pero también de propuestas de reconfiguración y formación de un sistema mediático-digital pluralista, diverso $\mathrm{y}$ participativo, entre las que compilamos:

- Implantación en educación inicial, básica, diversificada y universitaria de asignaturas o componentes transversales en materia de educación en medios, alfabetización mediática, digital e informacional.
- Educación mediática, digital e informacional desde una política pública activa que fomente la formación crítica, participativa y creativa de la ciudadanía.

- Promoción de programas educativos que conjuguen la formación crítica con el periodismo interpretativo $\mathrm{y}$ de investigación.

- Fomento, a través de ayudas públicas, subvenciones o beneficios impositivos, de medios de comunicación y productoras de contenidos educativos y culturales de calidad.

- Rescate de la esencia de los medios de comunicación como servicio público.

- Establecer límites legales a la programación de entretenimiento, buscando el equilibrio entre contenidos informativos, educativos $\mathrm{y}$ de ocio en los horarios de mayor audiencia. 


\section{Discusión y conclusiones}

El actual ecosistema comunicacional y digital lleva consigo una carga desinformativa endógena del trinomio contentivo de la sobresaturación, la mediamorfosis y los ingentes pseudo-contenidos, razones por las cuales ha de constituirse desde la audiencia y la política de comunicación, el marco operativo y las barreras de protección necesarias para hacer frente, o al menos atenuar, los efectos desinformativos endémicos.

En primer lugar, para combatir la sobresaturación del espectro informativo y la

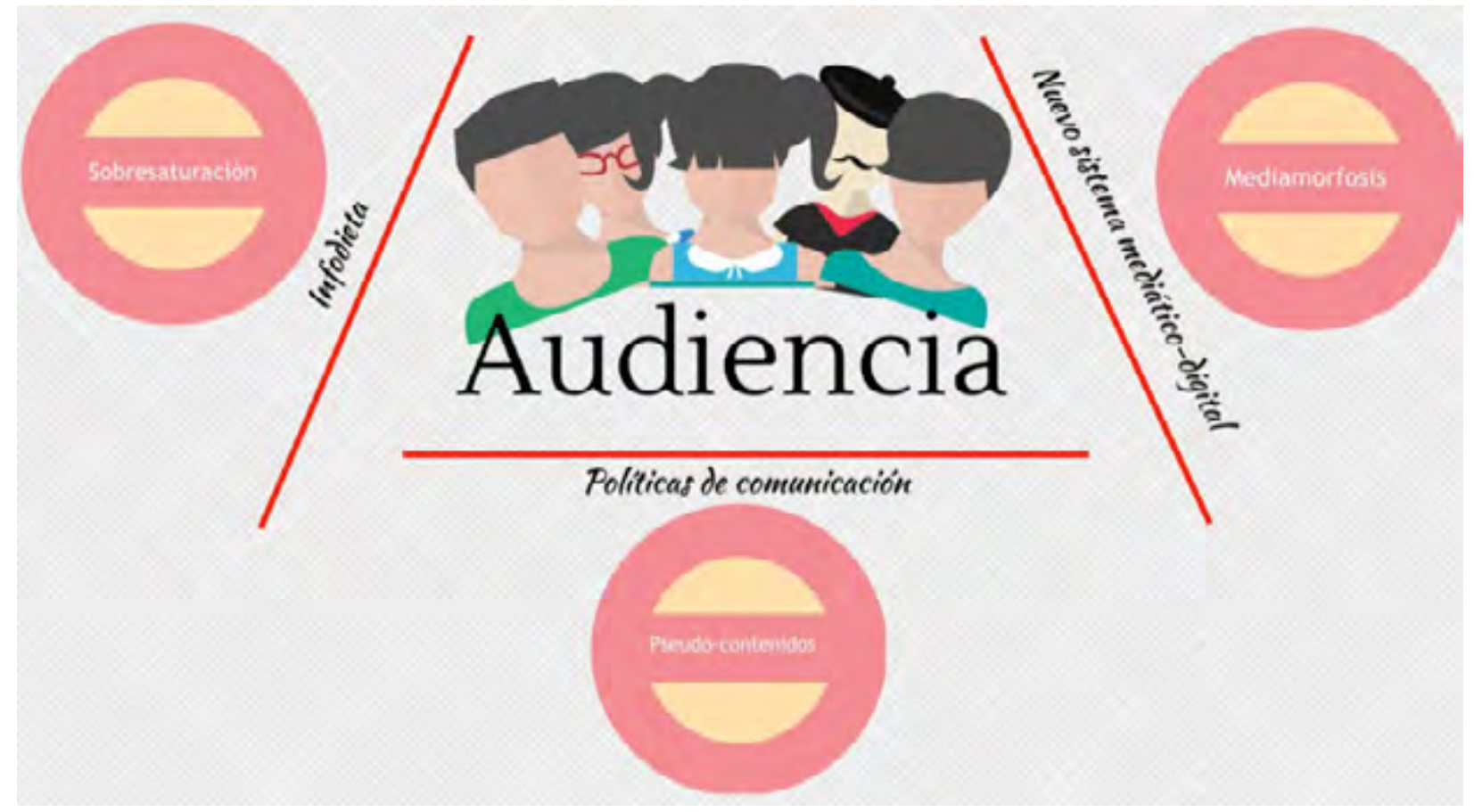

Figura 1. Barreras de protección de las audiencias en el ecosistema comunicacional-digital.

colonización de nuestras propias realidades e interacciones por el uso excesivo de las tecnologías, es menester estructurar una ecología de medios o "infodieta" que equilibre tanto la relación cuanti-cualitativa de la información que recibimos, como también nos permita desinfoxicarnos paulatinamente de la sobrecarga de contenidos vacíos, bien sea para invertir dicho tiempo en cuestiones que sean útiles -relaciones familiares, sociales, productividad y actividad física-, como también para generar un distress y una reducción de la dependencia tecnológica, a la vez de aprender a aprovechar los momentos de conexión con mayor idoneidad.

En segundo término, la mediamorfosis es una circunstancia propia de los cambios que se suscitan dentro de los medios del ecosistema, lo que depende directamente de los hábitos de consumo y de la lucha que mantienen los medios tradicionales por la adaptación al nuevo entorno. Como consecuencia, la pregunta sobre la necesidad de trabajar en conjunto la alfabetización mediática, digital e informacional no está en discusión, con el fin de dotar a la audiencia de herramientas para acceder a los medios con responsabilidad, a la vez de contrarrestar la pasividad, inercia e ingenuidad en la recepción de los mensajes. Por supuesto, el llamado no solo es en este caso a la responsabilidad educativa, sino a un fomento de adeudo socialmediático por parte de las instituciones públicas y la educación en el contexto familiar.

Por último, hacer frente a la dinámica de hiperproducción de pseudo-contenidos o contenidos vacíos únicamente puede venir desde las audiencias, pues la lógica transversal de los mercados actuales favorece el desarrollo de este tipo de programación y conteni-dos. Para ello, al igual que en el punto anterior, hace falta promover actividades de alfa- 
betización del consumo de medios, a la vez de políticas de comunicación enmarcadas al beneficio de producción de contenidos educativos, informativos y culturales de calidad, desde el pluralismo, la participación ciudadana y los medios con una perspectiva de servicio público.

\section{Referencias}

Aguaded, JI. (2014). Desde la infoxicación al derecho a la comunicación. Comunicar, 4(21), 7-8. http://doi.org/vgx.

Alexa. (2014). Actionable Analytics for the Web: Buzzfeed.com. Recuperado el 21 de diciem-bre de 2014 de: http://goo.gl/crPCV3

Arráez, R., (1998). La comunicación para el desarrollo. Su aplicación para el medio radio. Revista Latina de Comunicación Social, 9 (1).

Asociación de la Prensa de Madrid. (2013). Informe anual de la profesión periodística. Recuperado el 20 de diciembre de 2014 de: http://goo.gl/inykkI

Badke, W. (2009). Media, ICT, and Information Literacy. Online, 3(5), 47-49.

Boekhorst, A.K. (2012). (M)IL and its Kind. International Conference of the Media and Infor-mation Literacy for Knowledge Society (Moscow).

Cáceres-Zapatero, M.D. (2013). El discurso de los expertos a propósito de la telerrealidad. Estudios sobre el mensaje periodístico, 20(2), 661-676.

http://doi.org/xv7

Cornella, A. (2010). Infoxicación: Buscando un orden en la información. Barcelona: Infonomía.

De-Pablos, J. \& Mateos-Martín, C. (2004). Estrategias informativas para acceder a un periodis-mo de calidad, en prensa y TV: Patologías y tabla de mediación para recuperar la calidad en prensa. Ámbitos, 1112, 341-365.

Etling, B., Kelly, J., Faris, R. \& Palfrey, J. (2009). Mapping the Arabic Blogosphere: Politics, Culture, and Dissent. Harvard University: The Berkman Center for Internet and Socie-ty. Recuperado el 18 de diciembre de 2014 de:

http://goo.gl/pbQKZv

Floridi, L. (2014). L'informazione trasdiegetica. Lectio magistralis di Luciano Floridi. Universitá Degli Studi di Ferrara. Recuperado el 20 de diciembre de 2014 de: http://goo.gl/OCc8Px

Freeman, J. (2009). The Tyranny of E-mail: The Four-Thousand-Year Journey to Your Inbox. Nueva York: Scribner

Hanson, J. (2007). 24/7: How Cell Phones and the Internet Change the Way We Live, Work and Play. Westport, USA: Praeger Publishers

Honoré, C. (2004). In Praise of Slowness. Nueva York: Harper Collins.

Humanes, M. L. (2006). La Anarquía Periodística: Por qué le llaman información cuando quieren decir... En F. Ortega, Periodismo sin Información. (pp. 51-75). Madrid: Tecnos.

IAB Europe. (2014). Mediascope Europe Bulletin. Recuperado el 19 de diciembre de 2014 de:

http://goo.gl/wXnqXI

Instituto Nacional de Estadística (INE). (2014). Encuesta sobre equipamiento y uso 
de tecnologías de información y comunicación en los hogares: Año 2014. Recuperado el 17 de diciembre de 2014 de:

http://goo.gl/8bGUiV

International Data Corporation. (2013). Amount of Global Data. Recuperado el 19 de diciembre de 2014 de:

http://goo.gl/4nYEx1

International Telecommunication Union (ITU). (2013). The World Telecommunication Indicators Database. Recuperado el 17 de diciembre de 2014 de

http://goo.gl/iMeCxF

Jacoby, J. (1977). Information Load and Decision Quality: Some Contested Issues. Journal of Marketing Research, 14(4), 569573.

http://dx.doi.org/10.2307/3151201

Jantz, G.L. (2012). \#Hooked: The Pitfalls of Media, Technology and Social Networking. Florida: Siloam Press.

Johnson, C. A. (2012). The Information Diet: A Case for Conscious Consumption. San Francisco: O'Reilly \& Associates.

Karlova, N. \& Fisher, K. (2012). "Plz RT": A Social Difussion Model of Misinformation and Disinformation for Understanding Human Information Behaviour. Proceedings of the ISIC2012 (Tokyo).

Lee, A.Y.L. \& So, C.Y.K. (2014). Alfabetización mediática y alfabetización informacional: simi-litudes y diferencias. Comunicar 21(42), 137-146.

http://dx.doi.org/10.3916/C42-2014-13

Lippman, W. (1922). Public Opinion. New York: McMillan.

Livingstone, S., Van Couvering, E.J. \& Thumim, N. (2005). Adult Media Literacy: A Review of the Literature. London: Ofcom.

López-García, A. (2004). La desinformación en la aldea global como forma de conocimiento. Ágora: Revista de Ciencias Sociales, 10, 1930 .

Malhotra, N. K. (1984). Reflections on the Information Overload Paradigm in Consumer Deci-sion Making. Journal of Consumer Research, 4(10), 436-440.

http://dx.doi.org/10.1086/208982

Marcuse, H. (1968). Elhombre unidimensional. México: Ariel.

Milgram, S. (2010). The Individual in a Social World: Essays and Experiments. Londres: Print-er\&Martin.

Nielsen. (2014). Nielsen World Internet Stats. Nielsen Corporation. Recuperado el 19 de diciembre de 2014 de:

http://goo.gl/P75CTk.

Ortega, F. (2006). Periodismo sin información. Madrid: Tecnos.

Palomo, M.A. (2014). Telerrealidad: Las pantallas son suyas. El País. Recuperado el 21 de di-ciembre de 2014 de: http://goo.gl/ PlxR9e

Pérez-Latre, F.J. (2011). Paradojas de la comunicación digital. Aceprensa, 29 julio 2011. Recuperado el 14 de diciembre de 2014 de:

http://goo.gl/hiRqkX

Pérez-Rodríguez, MA. (2003). La paradoja de la comunicación sin fronteras. La "fractura digital". Portularia, 3, 299-310.

Pérez-Tornero, JM. (2005). El futuro de la sociedad digital y los nuevos valores de la educación en medios. Comunicar, 25, 247258.

Romero-Rodríguez, L. (2014). Pragmática de la desinformación: Estratagemas e incidencia de la calidad informativa de los medios. Tesis Doctoral. Universidad de Huelva: Repositorio Institucional Arias Montano. Recuperado el 
22 de diciembre de 2014 de:

http://goo.gl/gzy95A

Rotten, J., Olszewski, D., Charleton, M. \& Soler, E. (1978). Loud Speech, Conglomerate Noise, and Behavioral Aftereffects. Journal of Applied Psychology, 6(3), 360-365.

Sartori, G. (1998). Homo Videns: La Sociedad Teledirigida. Madrid: Taurus.

http://dx.doi.org/10.1037/00219010.63.3.360

Searle, J.R. (1997). La construcción de la realidad social. Barcelona: Paidós.

Serrano-Puche, J. (2013). Hacia una "comunicación slow": El hábito de la desconexión digital periódica como elemento de alfabetización mediática. Trípodos, 34, 201-214.

Serrano-Puche, J. (2014). Por una dieta digital: hábitos mediáticos saludables contra la "obesidad informativa". Ambitos, 24.

Shenk, D. (2003). Information Overload, Concept of. En E. Science, Encyclopedia of Interna-tional Media and Communications, 2, 396-399. Boston: Elservier.

Soengas, X. (2013). El papel de Internet y de las redes sociales en las revueltas árabes: Una alternativa a la censura de la prensa oficial.
Comunicar, 4(21), 147-155.

http://doi.org/xvq

Stewart, T. R., Moninger, W. R., Heideman, K., \& Reagan-Cirincione, P. (1992). Effects of Improved Information on the Components of Skill in Weather Forecasting. Organiza-tional Behavior and Human Decision Processes, 53, 107-134.

http://dx.doi.org/10.1016/07495978(92)90058-F

Thom, R. (1992). Pouvoirs de la forme. Paris: Aarhus University.UNESCO (2012). Media and Information Literacy. Communication and Information. Recuperado el 2 de diciembre de 2014 de:

http://goo.gl/gaq2dT

Victoria-Mas, J.S., Gómez-Tinoco, A. \& Arjona-Martín, J.B. (2012). Comunicación "Slow" (y la publicidad como excusa). Madrid: Fragua.

Wajcman, J., Bittman, M. \& Brown, J. (2009). Intimate Connections: The Impact of the Mobile Phone on Work/Life Boundaries. En: Goggin, G.; Hjorth, L. (eds.). Mobile Technologies: From Telecommunications to Media. Nueva York: Routledge, 9-22.

Watzlawick, P. (1979). ¿Es real la realidad? Confusión, Desinformación, Comunicación. Barcelona: Heider. 